(C) Dereito Vol.28, n01:245-256 (Xaneiro-Xuño, 2019) • ISSN 1132-9947

\title{
DERECHOS HUMANOS Y POBREZA: UNA LECTURA DESDE LA CORTE INTERAMERICANA DE DERECHOS HUMANOS
}

Human rights and poverty: a reading from the Inter-American Court of Human Rights

DOI: http://dx.doi.org/10.15304/dereito.28.1.5671

Camila Agustina Ormar ${ }^{1}$

Doctoranda en Derecho

Universidad de Buenos Aires (Argentina)

Camila.ormar@azul.der.unicen.edu.ar

\section{Resumen}

En el presente trabajo me propongo como objetivo central explorar algunas posibles relaciones entre pobreza y derechos humanos en el Sistema Interamericano de Protección de los Derechos Humanos (SIPDH). En particular, consideraré la jurisprudencia desarrollada por la Corte Interamericana de Derechos Humanos (Corte IDH) en relación con las disposiciones establecidas en la Convención Americana sobre Derechos Humanos (CADH).

Palabras clave: Derechos humanos; Pobreza; Corte IDH; CADH.

\section{Abstract}

In the present work I propose as a central objective to explore some possible relationships between poverty and human rights in the InterAmerican System for the Protection of Human Rights (SIPDH). In particular, I will consider the jurisprudence developed by the InterAmerican Court of Human Rights (I / A Court HR) in relation to the provisions established in the American Convention on Human Rights (ACHR).

Keywords: Human rights; Poverty; IHR Court; ACHR.

\section{SUMARIO}

1.- CONSIDERACIONES INICIALES. 2.- RELACIÓN ENTRE DERECHOS HUMANOS $Y$ POBREZA EN LA JURISPRUDENCIA DE LA CORTE IDH ANTERIOR A 2016. 3 POBREZA Y DISCRIMINACIÓN POR MOTIVOS BASADOS EN LA POSICIÓN ECONÓMICA. 4.- CONCLUSIONES. 5.REFERENCIAS BIBLIOGRÁFICAS.

\section{CONSIDERACIONES INICIALES}

En el año 1945 -mismo año en que nació la Declaración Universal de Derechos Humanos- la Organización de Estados Americanos (OEA) promovió la creación de la Declaración Americana de los Derechos y Deberes del Hombre (DADDH) en cuyo preámbulo se otorgó un papel central a la dignidad de la persona humana. Más de dos décadas después,

\footnotetext{
${ }^{1}$ Abogada (UNICEN). Becaria Doctoral CONICET
}

Recibido: 28/01/2019. Aceptado: 15/05/2019. 
se redactó la Convención Americana sobre Derechos Humanos (CADH) que entró en vigencia en 1978, en cuyo texto también se enuncian derechos en favor de las personas y obligaciones a cargo de los Estados.

En este contexto, con el nacimiento del DIDH como rama del derecho internacional público (DIP) «el Estado comienza así, a ser desplazado del centro de la escena internacional y su lugar ocupado por los individuos. Bajo el nuevo paradigma se construye un derecho, ya no en vista del Estado, sino en interés de las personas. La formación y consolidación de los sistemas internacionales de protección demuestran, por sí mismos, el cambio de paradigma en el derecho internacional. El reconocimiento a las personas del derecho a peticionar ante dichos sistemas es una síntesis del cambio de época. Lo dicho implica, en los hechos, la posibilidad de denunciar a los Estados que han ratificado instrumentos internacionales en materia de derechos humanos» ${ }^{2}$.

En este orden de ideas, unos de los pilares centrales sobre los que descansa el DIDH -junto con el principio de igualdad y universalidad- es la dignidad intrínseca de las personas. Al respecto, «la noción de derechos humanos supone la protección de la libertad y la dignidad de todas las personas -hombres, mujeres y niños- en condiciones de igualdad, sin admitir ninguna distinción que tenga por objeto menoscabar la mencionada protección, con alcance universal -todas las personas, en todo el mundo, todos los derechos- y su violación no reparada compromete la responsabilidad internacional del Estado». ${ }^{3}$ En efecto, los sistemas de protección de los derechos humanos han advertido la centralidad que juega la dignidad al momento de considerar presuntas violaciones a disposiciones consagradas en diversos instrumentos internacionales. ${ }^{4}$ En otras palabras, la dignidad ha contribuido en gran medida a fundamentar y garantizar la efectiva tutela de los derechos humanos, es por ello que, cuando se analizan vulneraciones a derechos humanos en contextos de pobreza aquel concepto adquiere un rol central. Si bien es complejo brindar una única definición acabada de pobreza ${ }^{5}$ con frecuencia se destaca puntos de encuentro entre las diversas conceptualizaciones que se proponen de la misma. A modo de ejemplo, Faur afirma «Las múltiples definiciones de pobreza tienen en común la evidencia de una carencia, de un déficit para acceder a niveles de vida dignos». ${ }^{6}$ En tal sentido, tomando en cuenta la estrecha relación entre

2 C. PIZZOLO, Comunidad de intérpretes finales. Relación entre tribunales supranacionales, constitucionales y supremos. El dialogo judicial, Astrea, Buenos Aires, Argentina, 2017, pág. 13-14.

${ }^{3}$ M. PINTO, "Los derechos humanos desde la dimensión de la pobreza", Revista IIDH, 48, 44.

4 CORTE IDH. Caso Servellón García y otros Vs. Honduras. Sentencia de 21 de septiembre de 2006. Serie C No. 152. Disponible en: http://www.corteidh.or.cr/docs/casos/articulos/seriec_152_esp.pdf

${ }^{5}$ Algunas de las distintas definiciones de pobreza se pueden consultar en: CIDH, Pobreza y derechos humanos, OEA/Ser.L/V/II.164, 2017, pág. 21-39. Disponible en: http://www.oas.org/es/cidh/informes/pdfs/PobrezaDDHH2017.pdf.

${ }^{6}$ E. FAUR, "La pobreza como problema de derechos humanos. Nuevas orientaciones para históricas privaciones", Revista IIDH, 47, 2008, 165-182. 
dignidad y pobreza, asumo para el presente trabajo que la pobreza es una problemática susceptible de ser abordada jurídicamente desde el DIDH. Así, se ha advertido sobre la existencia de un consenso en torno a que «la pobreza y particularmente la extrema pobreza no sólo está referida a un problema económico, sino a uno más complejo que abarca diferentes esferas, como la social y la cultural, convirtiéndose también en un problema político, que afecta directamente el desarrollo humano y, por tanto, la satisfacción de los derechos humanos».7 Pese a la existencia de un acuerdo respecto de la necesidad de abordar la pobreza desde el plano jurídico, lo cierto es que aún no existe consenso en cuanto a la forma en que debe realizarse el mismo. ${ }^{8}$

Así, mi objetivo en esta oportunidad será explorar las distintas relaciones que surgen entre pobreza y derechos humanos en el SIPDH. Se considerará la jurisprudencia desarrollada por la Corte IDH -puntualmente en sus sentencias de fondo- en relación con las disposiciones establecidas en la CADH. A los efectos de adoptar un criterio que permita ordenarme, organizaré el presente trabajo de la siguiente manera: en primer lugar, analizaré aquellas sentencias de la Corte IDH en las cuales ha tomado en cuenta las condiciones de pobreza que las víctimas afrontaban para declarar la violación de derechos consagrados en la CADH. Luego, expondré a la pobreza como un componente de la prohibición de discriminación por «posición económica» en los términos del artículo 1.1 de la CADH tal como lo ha hecho la Corte IDH a partir de su sentencia al caso Hacienda Brasil Verde contra Brasil del año 2016. Finalmente, enunciaré las conclusiones alcanzadas.

\section{RELACIÓN ENTRE DERECHOS HUMANOS Y POBREZA EN LA JURISPRUDENCIA DE LA CORTE IDH ANTERIOR A 2016}

Una lectura detallada de la CADH permite advertir que el término pobreza no aparece mencionado en ningún artículo de dicho instrumento. De hecho, tampoco surgen de los trabajos preparatorios referencias concretas a la pobreza que permitan inferir una relación certera con posibles afectaciones a derechos humanos. ${ }^{9}$ En la misma línea de ideas, el término posición económica como categoría sospechosa contenida en el artículo 1.1 de la CADH -ausente en otros instrumentos regionales como el Convenio Europeo de Derechos Humanos- solo figura 5 veces a lo largo de los trabajos preparatorios sin que su contenido o definición haya pasado siquiera advertido por las delegaciones de los Estados. En definitiva, no existieron dudas acerca de la inclusión de la posición económica como uno de los motivos prohibidos de discriminación, pero la ausencia de discusión impide saber si, desde una interpretación histórica de la $\mathrm{CADH}$, es posible incluir a la pobreza dentro de la misma.

\footnotetext{
7 E. DULITZKY, "Pobreza y derechos humanos en el sistema interamericano. Algunas aproximaciones preliminares", Revista IIDH, 48, 2008, 107.

8 J. P. BECA-FREI, "Pobreza: un problema de derechos humanos. ¿Qué hacer cuando la legislación profundiza la pobreza?" Díkaion, 27(1), 2018, $101-126$.

OEA, Conferencia especializada interamericana sobre derechos humanos. OEA/Ser.K/XVI/1.2, 1969, San José, Costa Rica.
} 
Ahora bien, a partir de una interpretación sistemática de la $C A D H$, se destaca en el preámbulo de dicho instrumento menciona la erradicación de la miseria como una condición sine qua non para la libertad de todas las personas: «De modo que se puede entender que la propia Convención llama a prestar atención a la relación entre pobreza y extrema pobreza y vigencia de los derechos humanos». ${ }^{10}$

Al igual que ha ocurrido con otras temáticas ${ }^{11}$ la Corte IDH ha saltado el cerco de la literalidad para incluir dentro de sus sentencias a la pobreza como un factor que influye al momento de considerar vulneraciones a los derechos establecidos en la CADH. En algunas de sus sentencias, el tribunal se ha valido de una interpretación evolutiva del artículo 4 de la CADH -que regula el derecho a la vida- ${ }^{12}$ mientras que, en otras ha desarrollado el contenido y alcance del artículo 1.1 en lo que hace a la posición económica como categoría sospechosa ${ }^{13}$ para incluir a la pobreza dentro de ella.

En consecuencia, parte de la doctrina ha elaborado criterios con el objetivo de sistematizar los distintos supuestos en los cuales la Corte IDH ha aludido a las condiciones de pobreza con base en la conexión normativa -es decir, la relación entre los derechos humanos reconocidos en el sistema interamericano y la pobreza ${ }^{14}$ - o con base en su vinculación o no con grupos históricamente vulnerables «el sistema interamericano ha comenzado a analizar esta relación desde las siguientes perspectivas: pobreza como violación per se de derechos humanos, la pobreza como causa de violación de derechos humanos, la pobreza como consecuencia o agravante de la violación de derechos humanos, la pobreza como agravante de la violación de derechos humanos». ${ }^{15}$

En este orden de ideas, uno de los casos más emblemáticos que han llegado al SIPDH fue Villagrán Morales y otros Vs. Guatemala del año 1999. ${ }^{16}$ En efecto, en la década de 1990 se desarrolló en Guatemala un patrón generalizado de acciones al margen de la ley, perpetradas por agentes policiales hacia los niños de la calle. Dichos actos incluían amenazas, detenciones, tratos crueles, inhumanos y degradantes y

10 E. DULITZKY, "Pobreza y derechos humanos en el sistema interamericano. Algunas aproximaciones preliminares", Revista IIDH, 48, 2008, 107-134.

11 ORMAR, "Pueblos indígenas y tribales: la interpretación del artículo 21 de la Convención americana sobre derechos humanos", Visioni LatinoAmericane è la rivista del Centro Studi per l'America Latina, 17, 2017, 45-58.

12 CORTE IDH. Caso de la "Masacre de Mapiripán" Vs. Colombia. Sentencia de 15 de septiembre de 2005. Serie C No. 134. Disponible en: http://www.corteidh.or.cr/docs/casos/articulos/seriec_134_esp.pdf

${ }^{13}$ CORTE IDH. Caso Trabajadores de la Hacienda Brasil Verde Vs. Brasil. Sentencia de 20 de octubre de 2016. Serie C No. 318. Disponible en: http://www.corteidh.or.cr/docs/casos/articulos/seriec_318_esp.pdf

14 E. DULITZKY, "Pobreza y derechos humanos en el sistema interamericano. Algunas aproximaciones preliminares", Revista IIDH, 48, 2008, 107.

${ }^{15}$ E. DULITZKY, "Pobreza y derechos humanos en el sistema interamericano. Algunas aproximaciones preliminares", Revista IIDH, 48, 2008, 107.

${ }_{16}$ CORTE IDH. Caso de los "Niños de la Calle" (Villagrán Morales y otros) Vs. Guatemala. Sentencia de 19 de noviembre de 1999. Serie C No. 63. Disponible en: http://www.corteidh.or.cr/docs/casos/articulos/seriec_63_esp.pdf 
homicidios como medio para contrarrestar la delincuencia y vagancia juvenil. En este contexto, en junio de 1990, una camioneta con agentes de seguridad estatales se acercó a cuatro de las víctimas del caso obligándolas a subir al mismo. Luego de estar retenidos por unas horas, los niños fueron asesinados.

Si bien en la sentencia no se menciona la palabra pobreza resulta interesante traer a colación el caso dado que allí se interpreta de forma amplia el contenido del artículo 4 de la CADH. En efecto, la Corte IDH afirmó de manera categórica la imposibilidad de admitir enfoques restrictos del derecho a la vida al mismo tiempo que destacó las obligaciones de los Estados de «garantizar la creación de las condiciones que se requieran para que no se produzcan violaciones de ese derecho básico». ${ }^{17}$ Con base en lo anterior, el juez Cançado Trindade -presidente en ese entonces de la Corte IDH- comenzó a esbozar una conexión entre la situación que afrontaban las víctimas y el derecho a la vida consagrado en los términos de la CADH: «En los últimos años, se han deteriorado notoriamente las condiciones de vida de amplios segmentos de la población de los Estados Partes en la Convención Americana, y una interpretación del derecho a la vida no puede hacer abstracción de esta realidad, sobre todo cuando se trata de los niños en situación de riesgo en las calles de nuestros países de América Latina. (...)». ${ }^{18}$

Siete años después la Corte IDH en su sentencia al caso Servellón García y otros Vs. Honduras retomó los estándares fijados en Villagrán Morales y otros Vs. Guatemala para señalar en forma expresa que «El Estado tiene la obligación de asegurar la protección de los niños y jóvenes afectados por la pobreza que estén socialmente marginados $y$, especialmente, evitar su estigmatización social como delincuentes». ${ }^{19}$ De manera tal que, si un Estado tiene conocimiento de niños en situación de riesgo afectados por factores que pueden inducirlos a cometer actos ilícitos debe extremar las medidas de prevención del delito reforzándose, por lo tanto, su posición de garante con miras a asegurar el interés superior del niño.

Asimismo, a lo largo de su jurisprudencia la Core IDH ha señalado el impacto desproporcionado que genera la pobreza en torno a la vulneración de derechos humanos de determinados grupos vulnerables, como ha sido el caso las personas con discapacidad. En el caso Ximenes Lopes Vs. Brasil, la Corte IDH destacó que «Es directo y significativo el vínculo

\footnotetext{
17 CORTE IDH. Caso de los "Niños de la Calle" (Villagrán Morales y otros) Vs. Guatemala. Sentencia de 19 de noviembre de 1999. Serie C No. 63. Disponible en: http://www.corteidh.or.cr/docs/casos/articulos/seriec_63_esp.pdf

${ }^{18}$ CORTE IDH. Caso de los "Niños de la Calle" (Villagrán Morales y otros) Vs. Guatemala. Sentencia de 19 de noviembre de 1999. Serie C No. 63. Disponible en: http://www.corteidh.or.cr/docs/casos/articulos/seriec_63_esp.pdf

19 CORTE IDH. Caso Servellón García y otros Vs. Honduras. Sentencia de 21 de septiembre de 2006. Serie C No. 152. Disponible en: http://www.corteidh.or.cr/docs/casos/articulos/seriec_152_esp.pdf
} 
existente entre la discapacidad, por un lado, y la pobreza y la exclusión social, por otro». ${ }^{20}$

Finalmente es importante mencionar el caso Gonzales Lluy y otros Vs. Ecuador cuya sentencia de la Corte IDH data del año $2015 .{ }^{21}$ En su sentencia, el tribunal consideró que la víctima sufrió una discriminación derivada no solo de su condición de persona viviendo con VIH, de niña y de mujer, sino también por condición de pobreza, siendo la primera sentencia en la cual adopta el concepto de «interseccionalidad» para examinar la discriminación sufrida por la niña. En palabras de la Corte IDH «La discriminación que vivió Talía no sólo fue ocasionada por múltiples factores, sino que derivó en una forma específica de discriminación que resultó de la intersección de dichos factores, es decir, si alguno de dichos factores no hubiese existido, la discriminación habría tenido una naturaleza diferente. En efecto, la pobreza impactó en el acceso inicial a una atención en salud que no fue de calidad y que, por el contrario, generó el contagio con VIH. La situación de pobreza impactó también en las dificultades para encontrar un mejor acceso al sistema educativo y tener una vivienda digna».22

\section{POBREZA Y DISCRIMINACIÓN POR MOTIVOS BASADOS EN LA POSICIÓN ECONÓMICA}

En el año 2016 la Corte IDH inauguró una nueva etapa en el tratamiento de la pobreza y su relación con la vulneración a derechos consagrados en la CADH. El 20 de octubre de 2016 en la sentencia al caso Trabajadores de la Hacienda Brasil Verde Vs. Brasil ${ }^{23}$ por primera vez se declaró responsable internacionalmente a un Estado como consecuencia de la discriminación en razón de la posición económica que afrontaban las ochenta y cinco víctimas en los siguientes términos: «El Estado es responsable por la violación del artículo 6.1 de la Convención Americana, en relación con el artículo 1.1 del mismo instrumento, producida en el marco de una situación de discriminación estructural histórica, en razón de la posición económica de los 85 trabajadores identificados en el párrafo 206 de la presente Sentencia». ${ }^{24}$ Los hechos del caso versaron sobre la práctica de trabajo esclavo en la Hacienda Brasil Verde. La Corte IDH

${ }^{20}$ CORTE IDH. Caso Ximenes Lopes vs. Brasil. Sentencia de 4 de julio de 2006. Serie C No. 149.

Disponible

en:

http://www.corteidh.or.cr/docs/casos/articulos/Seriec_149_esp.pdf

${ }^{21}$ CORTE IDH. Caso Gonzales Lluy y otros Vs. Ecuador. Sentencia de 1 de septiembre de 2015. Serie C No. 298.2 Disponible http://www.corteidh.or.cr/docs/casos/articulos/seriec_298_esp.pdf

${ }^{22}$ CORTE IDH. Caso Gonzales Lluy y otros Vs. Ecuador. Sentencia de 1 de septiembre de 2015. Serie C No. 298.2 Disponible en: http://www.corteidh.or.cr/docs/casos/articulos/seriec_298_esp.pdf

${ }^{23}$ CORTE IDH. Caso Trabajadores de la Hacienda Brasil Verde Vs. Brasil. Sentencia de 20 de octubre de 2016. Serie C No. 318. Disponible en: http://www.corteidh.or.cr/docs/casos/articulos/seriec_318_esp.pdf

${ }^{24}$ CORTE IDH. Caso Trabajadores de la Hacienda Brasil Verde Vs. Brasil. Sentencia de 20 de octubre de 2016. Serie C No. 318. Disponible en: http://www.corteidh.or.cr/docs/casos/articulos/seriec_318_esp.pdf 
analizó la situación de los trabajadores de la Hacienda Brasil Verde a la luz de las disposiciones contenidas en el artículo 1.1 de la $\mathrm{CADH}$, en particular, a través del principio de no discriminación por motivos basados en la posición económica.

Vale recordar que el artículo 1.1 de la CADH establece las obligaciones de respeto y garantía en el pleno goce y ejercicio de los derechos establecidos en dicho tratado sin discriminación alguna, por lo que existe un vínculo indisoluble entre la obligación de respetar y garantizar los derechos humanos y el principio de igualdad y no discriminación (Corte IDH, 2003). De modo que la discriminación, con base en los motivos establecidos en el artículo 1.1 de la $\mathrm{CADH}$, debe ser justificada por el Estado de manera objetiva y razonable (Corte IDH, 2003) para considerar que no se viola el derecho a la igualdad en cuanto al disfrute y garantía de los derechos humanos.

En relación con la situación específica en la que se encontraban las víctimas del caso, la Corte IDH remarcó una serie de características particulares que las mismas reunían y que los colocaba en una situación que los hacía más susceptibles de ser reclutados mediante engaños: «De la prueba aportada al expediente se advierte la existencia de una situación basada en la posición económica de las víctimas rescatadas el 15 de marzo de 2000 que caracterizó un trato discriminatorio. De acuerdo a varios informes de la OIT y del Ministerio de Trabajo de Brasil, «la situación de miseria del obrero es lo que le lleva espontáneamente a aceptar las condiciones de trabajo ofrecidas», toda vez que «cuanto peores las condiciones de vida, más dispuestos estarán los trabajadores a enfrentar riesgos del trabajo lejos de casa. La pobreza, en ese sentido, es el principal factor de la esclavitud contemporánea en Brasil, por aumentar la vulnerabilidad de significativa parte de la población, haciéndoles presa fácil de los reclutadores para trabajo esclavo». ${ }^{25}$ Con base en lo anterior, la Corte IDH entendió, por primera vez, que un Estado era responsable internacionalmente por vulnerar el derecho contenido en el artículo 6 de la CADH -prohibición de esclavitud y servidumbre- en relación con el artículo 1.1 del mismo instrumento dada la situación de discriminación estructural que sufrían las víctimas del caso en razón de la posición económica de las mismas.

De esta forma, el catálogo que contiene los motivos por los cuales se encuentra prohibido discriminar en los términos del 1.1 de la CADH se amplió para incluir, dentro de la posición económica, a la pobreza como categoría protegida. En tal sentido, la Corte IDH ha sostenido en reiteradas oportunidades que el listado de criterios específicos previsto en el artículo 1.1 de la CADH no se constituye como taxativo, sino que únicamente se presenta a modo enunciativo. De este modo, se han incluido categorías como la orientación sexual y la identidad de género a

${ }^{25}$ CORTE IDH. Caso Trabajadores de la Hacienda Brasil Verde Vs. Brasil. Sentencia de 20 de octubre de 2016. Serie C No. 318. Disponible en: http://www.corteidh.or.cr/docs/casos/articulos/seriec_318_esp.pdf 
partir de la sentencia al caso Atala Rifo y niñas Vs. Chile ${ }^{26}$ o la discapacidad desde la sentencia Ximenes Lopez Vs. Brasil ${ }^{27}$ de 2006 entendiendo, por tanto, que la propia $\mathrm{CADH}$ permite la inclusión de categorías no previstas expresamente en su artículo 1.1 .

La inclusión de la pobreza como categoría sospechosa dentro de la posición económica mencionada en el artículo $1.1 \mathrm{CADH}$ representa un claro avance al visibilizar con mayor claridad la incidencia de la pobreza en la vulneración de derechos humanos, dada la transversalidad propia del 1.1 CADH hacia todo el catálogo de derechos que ésta consagra.

Más allá de los avances que implica la inclusión de la pobreza bajo la protección que aseguran las disposiciones contenidas en el artículo 1.1 de la $\mathrm{CADH}$, la determinación de la existencia de un contexto de discriminación estructural histórica en razón de la posición económica de las víctimas, en los términos que ha adoptado la Corte IDH en el párrafo 343 de la sentencia bajo análisis, ha resultado uno de los puntos más controversiales del fallo. El juez Sierra Porto en su voto parcialmente disidente destacó «No obstante que la determinación de violación se hace referente de los 85 trabajadores, no es claro si para la existencia de esa «discriminación estructural histórica» en particular respecto de ellos, es necesaria la existencia de una «discriminación estructural histórica» general en contra de toda persona en situación de pobreza en Piauí. El argumento realizado por la Corte parecería indicar que en todos los casos en que las víctimas compartan una característica en común (que los podría situar en una situación de vulnerabilidad), por ese solo hecho, existirá automáticamente discriminación estructural. En segundo lugar, considero que las características en común que compartían los trabajadores en el presente caso no son factores suficientes como para declarar la existencia de discriminación estructural en su contra. Si bien es cierto que, en general, los trabajadores sometidos a condiciones análogas a la esclavitud compartían algunas características, estas características son también compartidas por un gran número de personas en Brasil, que viven en situación de pobreza y cuentan con bajos niveles de escolaridad. En ese sentido, no resulta correcto concluir la existencia de discriminación estructural histórica en contra de los trabajadores de la Hacienda Brasil Verde en el presente caso». ${ }^{28}$

Surge la duda acerca de si, para declarar la vulneración a las disposiciones contenidas en el 1.1 en razón de la posición económica es necesario o no determinar si existe una situación estructural $y$, en ese caso, nace un segundo interrogante vinculado a cómo probar tal situación. Una posible

26 CORTE IDH. Caso Atala Riffo y niñas Vs. Chile. Fondo, Reparaciones y Costas. Sentencia del 24 de febrero de 2012. Serie C No. 239. Disponible en: http://www.corteidh.or.cr/docs/casos/articulos/seriec_239_esp.pdf

${ }^{27}$ CORTE IDH. Caso Ximenes Lopes vs. Brasil. Sentencia de 4 de julio de 2006. Serie C No. 149. Disponible

en: http://www.corteidh.or.cr/docs/casos/articulos/Seriec_149_esp.pdf

${ }^{28}$ CORTE IDH. Caso Trabajadores de la Hacienda Brasil Verde Vs. Brasil. Sentencia de 20 de octubre de 2016. Serie C No. 318. Disponible en: http://www.corteidh.or.cr/docs/casos/articulos/seriec_318_esp.pdf 
respuesta se da en el caso Ramírez Escobar y otros Vs. Guatemala cuya sentencia data de marzo de $2018 .^{29}$ Los hechos del caso se vinculaban con la separación de dos niños de su familia de origen quienes fueron adoptados por dos familias estadounidenses distintas en junio de 1998. Pese a los recursos presentados por los padres de los niños, el proceso de revisión se archivó en 2002, dado que no se habían sufragado los gastos asociados a la citación de los padres adoptivos de los niños Ramírez en los Estados Unidos de América.

En esta oportunidad, la Corte IDH fue más precisa al momento de analizar si existió o no discriminación en razón de la posición económica de las víctimas, avanzando en torno a los puntos marcados por el juez Sierra Porto en la sentencia al caso Haciende Brasil Verde Vs. Brasil. Así, el tribunal consideró dos criterios a examinar: «(i) el contexto de pobreza en los procedimientos de abandono y adopción en Guatemala en la época de los hechos, y (ii) si se utilizó la posición económica de la familia Ramírez como justificación para la separación de los niños de su familia biológica». ${ }^{30}$

En cuanto al primero, la Corte IDH destacó la situación de pobreza de un alto porcentaje de la población de Guatemala influyó en el contexto de adopciones ilegales en la época de los hechos: «iii) había una tendencia en los procesos de declaratoria de abandono y adopción de considerar la falta de recursos económicos de la madre como un factor predominante para separar a la niña o al niño de su familia e incluirlos en programas de adopción, y iv) la falta de medios económicos a la vez dificultaba la búsqueda de un recurso judicial para recuperar el cuidado de sus hijos». ${ }^{31}$ Una vez examinado el contexto general en el Estado, la Corte IDH trasladó el análisis a la situación en particular de las víctimas. Con base en la prueba aportada respecto de los informes sociales realizados en sede interna para declarar el estado de abandono de los niños el tribunal concluyó que la decisión de separación de la familia Ramírez constituyó una diferencia de trato fundamentada, entre otras razones, en la posición económica de sus miembros. A modo de ejemplo, «(ii) en un estudio social realizado por la Asociación Los Niños en mayo de 1997 sobre las madrinas de los niños (supra párr. 96), se indicó que «[l]os ingresos de cada grupo familiar son a todas luces insuficientes para cubrir las necesidades de cada familia y es evidente que no están en condiciones

${ }^{29}$ CORTE IDH. Caso Ramírez Escobar y otros Vs. Guatemala. Sentencia de 9 de marzo de 2018. Serie C No. $351 . \quad$ Disponible http://www.corteidh.or.cr/docs/casos/articulos/seriec_351_esp.pdf

${ }^{30}$ CORTE IDH. Caso Ramírez Escobar y otros Vs. Guatemala. Sentencia de 9 de marzo de 2018. Serie C No. $351 . \quad$ Disponible http://www.corteidh.or.cr/docs/casos/articulos/seriec_351_esp.pdf

${ }^{31}$ CORTE IDH. Caso Ramírez Escobar y otros Vs. Guatemala. Sentencia de 9 de marzo de 2018. Serie C No. 351. Disponible en: http://www.corteidh.or.cr/docs/casos/articulos/seriec_351_esp.pdf 
económicas de asumir la responsabilidad de criar y educar a otro niño».32 A la luz de lo anterior, la Corte IDH concluyó que la decisión de separar a los hermanos Ramírez de su familia se fundamentó en la situación económica de los distintos miembros, incluyendo su familia ampliada, representada por la abuela materna y las madrinas de los niños.

En definitiva, las sentencias Hacienda Brasil Verde Vs. Brasil y, Ramírez Escobar y otros Vs. Guatemala permiten advertir un claro avance de la Corte IDH en materia de pobreza y derechos humanos en el SIPDH. En primer lugar, ambas sentencias representan la inclusión de la pobreza como una categoría protegida por el artículo 1.1 de la CADH. Esto implica que, en caso de que exista un trato diferenciado basado en la condición económica hacia una persona o un grupo de personas, corresponderá al Estado en cuestión aportar las pruebas necesarias que permitan inferir que la distinción de trato resulta objetiva y proporcional.

En un principio se cuestionó la existencia de una situación estructural de pobreza y las dificultades que, a nivel jurídico, implican demostrar la existencia de la misma. Las dificultades se fueron sorteando en gran medida gracias a la reestructuración argumentativa que utilizó el tribunal para fundar su sentencia contra Guatemala. En efecto, luego de determinar que efectivamente existía un contexto de pobreza que influenciaba en las declaraciones de abandono de niños para su posterior adopción, la Corte IDH se dedicó a examinar si dicho contexto había repercutido en el caso que se encontraba entendiendo.

La tutela efectiva de los derechos humanos a nivel regional avanzó sin dejar de lado la seguridad jurídica ni legitimidad del propio SIPDH. El examen de un contexto generalizado sumado a la influencia del mismo en el caso concreto -análisis que la Corte IDH ha realizado desde sus iniciospermite llegar al mismo resultado que en la sentencia contra el Estado de Brasil -esto es, declarar responsable internacionalmente a un Estado por discriminación con base en la posición económica de un grupo de personas- sin necesidad de condenar a un Estado por la existencia de un patrón estructural cuya prueba resulta sumamente compleja aun ante instancia internacionales.

\section{CONCLUSIONES}

En el presente trabajo me propuse explorar las distintas relaciones que la Corte IDH ha establecido, en el marco de su competencia contenciosa, entre pobreza y vulneraciones a los derechos contenidos en la CADH. Con base en lo expuesto arribé a las siguientes conclusiones:

La ausencia de normativa que regule la pobreza como un obstáculo para el pleno goce y ejercicio de los derechos consagrados en la CADH no ha sido un límite para el tribunal al momento de entender sobre casos cuyas víctimas se encontraban en situaciones de vulnerabilidad por su condición de pobreza.

32 CORTE IDH. Caso Ramírez Escobar y otros Vs. Guatemala. Sentencia de 9 de marzo de 2018. Serie $C$ No. $351 . \quad$ Disponible en: http://www.corteidh.or.cr/docs/casos/articulos/seriec_351_esp.pdf 
Sin embargo, dentro de la jurisprudencia de la Corte IDH no existe un tratamiento homogéneo de todos los casos relativos a la afectación de derechos consagrados en la $\mathrm{CADH}$ y su relación con la pobreza. Así, advierto dos grandes líneas jurisprudenciales, a saber:

Hasta el año 2016, el tribunal fundó sus sentencias pensando a la pobreza como fenómeno transversal que afecta a una multiplicidad de derechos humanos. A modo de ejemplo, la Corte IDH ha vinculado a la pobreza con la afectación del derecho a la vida entendido en sentido amplio. De esta forma, ha abarcado aquellos supuestos en los cuales los Estados no hayan adoptado las medidas necesarias para garantizar niveles de vida dignos, siendo emblemático el caso Villagrán Morales y otros contra Guatemala. Por otro lado, la jurisprudencia interamericana ha considerado a la pobreza como un componente de la prohibición de discriminación por «posición económica» en los términos del artículo 1.1 de la CADH a partir de su sentencia al caso Hacienda Verde Vs. Brasil. En estos casos, el tribunal ha utilizado el artículo 1.1 de la CADH en el sentido de que los derechos consagrados en dicho instrumento deben ser garantizados a todas las personas bajo su jurisdicción sin discriminación alguna por motivos basados en la posición económica.

\section{REFERENCIAS BIBLIOGRÁFICAS}

C. PIZZOLO, Comunidad de intérpretes finales. Relación entre tribunales supranacionales, constitucionales y supremos. El dialogo judicial, Astrea, Buenos Aires, Argentina, 2017.

CIDH, Pobreza y derechos humanos, OEA/Ser.L/V/II.164, 2017. Disponible en: http://www.oas.org/es/cidh/informes/pdfs/pobrezaddhh2017.pdf

CORTE IDH. Caso Atala Riffo y niñas Vs. Chile. Fondo, Reparaciones y Costas. Sentencia del 24 de febrero de 2012. Serie C No. 239. Disponible en: http://www.corteidh.or.cr/docs/casos/articulos/seriec_239_esp.pdf

CORTE IDH. Caso de la "Masacre de Mapiripán" Vs. Colombia. Sentencia de 15 de septiembre de 2005. Serie C No. 134. Disponible en: http://www.corteidh.or.cr/docs/casos/articulos/seriec_134_esp.pdf

CORTE IDH. Caso de los "Niños de la Calle" (Villagrán Morales y otros) Vs. Guatemala. Sentencia de 19 de noviembre de 1999. Serie C No. 63. Disponible en: http://www.corteidh.or.cr/docs/casos/articulos/seriec_63_esp.pdf

CORTE IDH. Caso Gonzales Lluy y otros Vs. Ecuador. Sentencia de 1 de septiembre de 2015. Serie C No. 298. Disponible en: http://www.corteidh.or.cr/docs/casos/articulos/seriec_298_esp.pdf

CORTE IDH. Caso Ramírez Escobar y otros Vs. Guatemala. Sentencia de 9 de marzo de 2018. Serie C No. 351. Disponible en: http://www.corteidh.or.cr/docs/casos/articulos/seriec_351_esp.pdf

CORTE IDH. Caso Servellón García y otros Vs. Honduras. Sentencia de 21 de septiembre de 2006. Serie C No. 152. Disponible en: http://www.corteidh.or.cr/docs/casos/articulos/seriec_152_esp.pdf 
CORTE IDH. Caso Trabajadores de la Hacienda Brasil Verde Vs. Brasil. Sentencia de 20 de octubre de 2016. Serie C No. 318. Disponible en:

http://www.corteidh.or.cr/docs/casos/articulos/seriec_318_esp.pdf

CORTE IDH. Caso Ximenes Lopes vs. Brasil. Sentencia de 4 de julio de 2006. Serie C No. 149. Disponible en: http://www.corteidh.or.cr/docs/casos/articulos/Seriec_149_esp.pdf

E. DULITZKY, "Pobreza y derechos humanos en el sistema interamericano. Algunas aproximaciones preliminares", Revista IIDH, 48, 2008, 107134.

E. FAUR, "La pobreza como problema de derechos humanos. Nuevas orientaciones para históricas privaciones", Revista IIDH, 47, 2008, $165-182$.

J. P. BECA-FREI, "Pobreza: un problema de derechos humanos. ¿Qué hacer cuando la legislación profundiza la pobreza?" Díkaion, 27(1), 2018, $101-126$.

M. PINTO, "Los derechos humanos desde la dimensión de la pobreza", Revista IIDH, 48, 43-62.

OEA, Conferencia especializada interamericana sobre derechos humanos. OEA/Ser.K/XVI/1.2, 1969, San José, Costa Rica.

ORMAR, "Pueblos indígenas y tribales: la interpretación del artículo 21 de la Convención americana sobre derechos humanos", Visioni LatinoAmericane è la rivista del Centro Studi per l'America Latina, $17,2017,45-58$. 